\title{
28 Resarch Suare \\ Spinocerebellar Ataxia Type 28 in a Chinese Pedigree: A Case Report and Literature Review
}

\section{Linlin Wang}

China-Japan Union Hospital of Jilin University Department of Neurology

Xiaoyang Liu

China-Japan Union Hospital of Jilin University Department of Neurology

Jiajun Chen

China-Japan Union Hospital of Jilin University Department of Neurology

\section{Chunyang Kang}

China-Japan Union Hospital of Jilin University Department of Neurology

Jia Li ( $D$ lijia33233@jlu.edu.cn )

China-Japan Union Hospital of Jilin University https://orcid.org/0000-0002-3422-2125

\section{Brief report}

Keywords: spinocerebellar ataxia, pedigree, gene mutation

Posted Date: July 13th, 2021

DOI: https://doi.org/10.21203/rs.3.rs-671804/v1

License: () (1) This work is licensed under a Creative Commons Attribution 4.0 International License. Read Full License 


\section{Abstract}

Spinocerebellar ataxia (SCA) is a common neurogenetic disease, which mainly manifests as ataxia of posture, gait and limbs, cerebellar dysarthria, cerebellar and supranuclear eye movement disorders. It is found that SCA is a kind of progressive neurodegenerative disease including many subtypes, which is mainly mapped to two genetic patterns as: autosomal dominant cerebellar ataxia (ADCA) and autosomal recessive cerebellar ataxia (ARCA). Molecular genetic diagnosis functions as a necessity in its clinical diagnosis and treatment. In our previous clinical work, we found a family with ataxia who presented a c.1852A > G missense mutation in the exon region of AFG3L2 gene by whole exome sequencing (WES) and Sanger validation. Spinocerebellar ataxia type 28 (SCA28) was suspected, which was not reported in the previous literature. We here report the case and review the literature.

\section{Case Presentation}

The proband (III-3) $₫ 32$ year-old $₫$ male $\bigotimes$ visited the Department of Neurology of our hospital for "unsteady steps for more than 7 months". More than 7 months prior to the admission, the patient gradually had unsteady steps under no obvious predisposing causes, manifested as walking with a rolling gait. The patient's condition gradually worsened and manifested with increased step distance and drunken walking from side to side at admission. The patient complained of recent difficulties in eye opening, involuntary tremor of both upper limbs and catatonia, which were aggravated post activities.

Neurological examination: Conscious mind, dysarthria, normal memory, calculation and orientation power, normal visual acuity and field of both eyes, free movement of both eyes in all directions, horizontal nystagmus when both eyes look to the left, ptosis of both eyes, unstable and inaccurate bilateral finger-nose test, clumsy bilateral alternating movements, clumsy bilateral heel-knee-shin test and no bilateral pathological reflex.

Auxiliary examinations: Head magnetic resonance imaging (MRI) of the proband (III-3) showed cerebellar atrophy with no clear abnormal signals in the rest. Cervical MRI suggested no atrophy or thinning in cervical cord. (Figure 2).

Family surveys: Figure 1 shows the family history of the proband (III-3). The mother (II-3) developed similar symptoms in her 30s, was paralyzed in bed in following days and died in her 40s. The elder maternal uncle (II-2) and his children (III-1, III-2) have no clear clinical manifestations currently. The younger maternal uncle (II-5) began to suffer from illness in his 20 s and died from disease in his 30 s.

The daughter of the younger maternal uncle (III-5) (25-year-old now) gradually had unsteady steps and unclear speech with no obvious incentive at around 20 years old, manifested as a slightly wide step base, un-straight walking, influent speech, and appearance of choking cough in drinking water in the past year. Neurological examination: conscious mind, dysarthria, horizontal nystagmus when both eyes look to left and right, active tendon reflex of limbs, unstable and inaccurate bilateral finger-nose test, clumsy bilateral alternating movements and bilateral heel-knee-shin test. Auxiliary examination: head MRI suggested cerebellar atrophy (Figure 3).

With the informed consent of patients and their families, serum samples of the proband (III-3) and his cousin (III-5) were collected to identify genes involved in pathogenesis of SCA. The blood samples were sent to Beijing HighTrust Diagnostic for whole exome sequencing (WES). Sanger sequencing for the patients (III-3 and III-5) revealed a c.1852A > G missense mutation in the exon region of AFG3L2 gene, resulting in lysine-glutamate amino acid substitution (p.K618E) (Figures 4 and 5). Combined with the clinical manifestations, auxiliary examinations and sequencing results of the patients (III-3 and III-5), SCA28 was suspected. The mutation is not reported in the published literature and publicly available databases.

\section{Discussion}

SCA holds $10 \%-15 \%$ of the neurogenetic diseases with a prevalence rate of (1-4) /100,000 across all ethnic groups, while the prevalence rate varies significantly in different geographical regions and ethnic groups [7]. Numbered based on the order of 
discovered pathogenic genes, more than 40 types of SCA can be divided, including 46 loci/genes discovered and 35 causal genes identified [8]. Genetic diversity of SCA falls in trinucleotide repeat expansions (SCA1, 2, 3, 6, 7, 8, 12, 17 and dentatorubral-pallidoluysian atrophy [DRPLA]), pentanucleotide repeat expansions (SCA10 and 31), hexanucleotide repeat expansions (SCA36), conventional mutations (SCA5, 11, 13, 14, 15/16, 18, 19/22, 21, 23, 26, 27, 28, 29, 34, 35, 38 and 40), and types of unidentified responsible genes (SCA4, 20, 25, 30, 32 and 37) [9]. Of the current autosomal dominant SCA subtypes, only a small number of pathogenic genes are identified. As reported, clinically $20 \%-40 \%$ of SCA families are absent of gene mutations [10]. Varying functions of the disease-associated genes cause the complex heterogeneity of the pathogenesis behind cerebellar degeneration and ataxia.

SCA28 is the one uniquely caused by a pathogenic variation in the mitochondrial protein AFG3L2 [11]. AFG3L2 (ATPase family gene 3-like 2) belongs to the AAA protease subfamily (ATPase associated with various cellular activities) and involves in the assembly of m-AAA proteases in the inner mitochondrial membrane (IMM) being homo-and hetero-oligomers. m-AAA proteases are key parts for the quality control system of IMM that can mediate the selective degradation of unassembled and damaged proteins [12]. In addition, m-AAA proteases are also equipped with other functions, such as promoting mitochondrial protein synthesis [13], respiratory chain complex assembly [14], mitochondrial dynamics and mitochondrial calcium dynamic balance [15].

Pathogenic mutations of SCA28 are commonly reported to be heterozygous missense mutations within the key proteolytic domain coded by exons 15 and 16. Other mutations include a missense mutation in exons 4 [16] and 10 [11], a frameshift mutation in exon 15 [17], and a deletion spanning exons 14-16 [18]. Table 1 shows the literature review for pathogenic nucleotides. As displayed, the glycine to arginine substitution caused by c.2011G > C mutation is seen in the highly conserved peptidase-M41 region of the AFG3L2 protein [3]. SCA28 was first reported two years after the discovery of mutations on chromosomes 18p11.22-q11.2 [4], showing that the disease-associated variants on the chromosomes 18p11.22-q11.2 span the genomic DNA region of $7.9 \mathrm{Mb}$, manifested as $\mathrm{G}$ to $\mathrm{A}$ variant resulting in the substitution of glutamate and lysine residues [19]. Concurrent heterozygotes missense mutations (c.1847A > G [p.Y616C], c.2167G > A [p.V723M]) are rare, which decreases the levels of two mitochondrial proteins: TOMM70 (translocase of outer mitochondrial membrane 70) and respiratory chain complex V (ATPase), to cause mitochondrial structural defects and suppressed functions [6]. Heretofore, no dominant ataxia, except SCA28, has been identified to shown an association with mitochondrial dysfunction.

Although AFG3L2 gene variants are similar in variation type and position, the clinical phenotypes of SCA28 patients can be further modified by the severity of clinical symptoms and age of onset, including slow progressive gait abnormalities, ataxia, and oculomotor nerve abnormalities (such as ophthalmoplegia and ptosis) [20]. A large amount of research has shown that patients with SCA28 have normal cognitive function, while mild cognitive impairment or intelligence quotient decline is not common [21]. In the present report, c.1852A > G in the exon region of AFG3L2 gene was found in both the proband (III-3) and his cousin (III-5), resulting in a lysine-to-glutamate amino acid substitution (p.K618E). The clinical manifestations of the patients suggested SCA28, and such heterozygous mutation is not presented by any case report, which may provide a reference for future clinical diagnosis. Limitations of this report cannot be negated that, the sick relatives of the last generation of the proband are not available for gene sequencing due to their death and we failed to perform gene sequencing for more members of the family. Currently, the pathogenic mutation reported here has not been reported. We need to further genotype non-diseased members of the family and normal healthy individuals for this mutation, and carry out further research using cell and animal experiments to determine whether the missense mutation is responsible for the pathogenesis of SCA28.

Clinical manifestations of SCA patients are diverse. Certain feature is present in different SCA types, but the diagnosis of SCA must be referenced from molecular genetic examinations, rather than clinical manifestations or MRI presentations. There has been no specific treatment targeting SCA, while symptomatic treatment, such as drug treatment and rehabilitation treatment, is the mainstay but is not preventive for disease progression. Gene therapy is potentially the most ideal treatment option[22], yet sufficient clinical evidence should be gained to support its feasibility. Clinically, symptomatic treatment and achievement of symptom relief are the main strategies combating SCA, and genetic counseling and prenatal screening are encouraged for 
SCA patients and the healthy people in their families. Further study of molecular biology and genetics may extend our understanding on SCA and help find more reliable methods for effective prevention and treatment.

Table 1. Clinical manifestations of two patients in a SCA28 family.

\begin{tabular}{|c|c|c|c|c|c|c|c|c|c|c|}
\hline No. & $\begin{array}{l}\text { Onset } \\
\text { age }\end{array}$ & Ataxia & Dysarthria & Nystagmus & $\begin{array}{l}\text { Choking } \\
\text { and } \\
\text { cough } \\
\text { in } \\
\text { drinking } \\
\text { water }\end{array}$ & $\begin{array}{l}\text { Pyramidal } \\
\text { tract } \\
\text { signs }\end{array}$ & $\begin{array}{l}\text { Tendon } \\
\text { reflex }\end{array}$ & $\begin{array}{l}\text { Muscle } \\
\text { atrophy }\end{array}$ & Ptosis & Tremor \\
\hline $\begin{array}{l}\text { III- } \\
3\end{array}$ & $\begin{array}{l}32- \\
\text { year- } \\
\text { old }\end{array}$ & + & + & $\begin{array}{l}\text { Horizontal } \\
\text { nystagmus }\end{array}$ & + & - & Normal & - & + & + \\
\hline $\begin{array}{l}\text { III- } \\
5\end{array}$ & $\begin{array}{l}25- \\
\text { year- } \\
\text { old }\end{array}$ & + & + & $\begin{array}{l}\text { Horizontal } \\
\text { nystagmus }\end{array}$ & + & - & Active & - & - & - \\
\hline
\end{tabular}

Table 2 Literature review for gene pathogenic nucleotides

\begin{tabular}{|c|c|c|c|c|}
\hline Author & Publication & Country & Site & Clinical manifestations \\
\hline Cagnoli C[1] & 2010 & Italy & c. $2011 \mathrm{G}>\mathrm{A}$ & Not reported \\
\hline Gorman[2] & 2015 & England & c. $2011 \mathrm{G}>\mathrm{T}$ & Progressive external ophthalmoplegia (PEO) and ptosis \\
\hline Laszlo [3] & 2017 & Hungary & c. $2011 \mathrm{G}>\mathrm{C}$ & Ataxia, dysarthria and eye movement disorders \\
\hline Cagnoli[4] & 2006 & Italy & $\begin{array}{l}18 p 11.22- \\
\text { q11.2 }\end{array}$ & $\begin{array}{l}\text { Juvenile-onset and slow progress; nystagmus, dysarthria, } \\
\text { ataxia, tendon hyperreflexia, bilateral ankle clonus and } \\
\text { Babinski sign }\end{array}$ \\
\hline Ulf Edener[5] & 2010 & Germany & c. $2098 \mathrm{G}>\mathrm{A}$ & Early-onset slowly progressive cerebellar ataxia \\
\hline SinemTunc[6] & 2019 & Germany & $\begin{array}{l}\text { c. } 1847 \mathrm{~A}>\mathrm{G}, \\
\text { c. } 2167 \mathrm{G}>\mathrm{A}\end{array}$ & $\begin{array}{l}\text { Early-onset slowly progressive cerebellar ataxia, bilateral ptosis } \\
\text { and dysarthria }\end{array}$ \\
\hline
\end{tabular}

\section{Declarations}

\section{Ethics approval and consent to participate}

The study was conducted in accordance with the Declaration of Helsinki

Principles and approved by the ethics committee of the China-Japan Union

Hospital of Jilin University. Written informed consent was obtained from each

subject prior to inclusion in the study.

\section{Consent for publication}

The consent for publication was obtained from all participants. And written

consent for publication was also obtained.

\section{Availability of data and material}

The datasets generated during and analyzed during the current study are available from the corresponding author on reasonable request. 


\section{Competing interests}

The authors declare that they have no competing interests.

\section{Funding}

This study was supported by Jilin Science and Technology Department Project (No.20200201451JC)

\section{Authors' contributions}

LW analyzed and interpreted the patient data, and was a major contributor in

writing the manuscript.JL and $\mathrm{KC}$ guided the writing. $\mathrm{XL}$ and $\mathrm{JC}$ helped to analyz and

interpret the patient data. All authors read and approved the final manuscript.

\section{Acknowledgements}

We gratefully acknowledge XL囚JC for performing a

research on the questions and for conducting the literature search. We thank

all the study participants.

\section{References}

[1] C. Cagnoli, G. Stevanin, A. Brussino, M. Barberis, C. Mancini, R.L. Margolis, S.E. Holmes, M. Nobili, S. Forlani, S. Padovan, P. Pappi, C. Zaros, I. Leber, P. Ribai, L. Pugliese, C. Assalto, A. Brice, N. Migone, A. Durr, A. Brusco, Missense mutations in the AFG3L2 proteolytic domain account for approximately $1.5 \%$ of European autosomal dominant cerebellar ataxias, Hum Mutat $31(10)(2010)$ 1117-24.

[2] G.S. Gorman, G. Pfeffer, H. Griffin, E.L. Blakely, M. Kurzawa-Akanbi, J. Gabriel, K. Sitarz, M. Roberts, B. Schoser, A. Pyle, A.M. Schaefer, R. McFarland, D.M. Turnbull, R. Horvath, P.F. Chinnery, R.W. Taylor, Clonal expansion of secondary mitochondrial DNA deletions associated with spinocerebellar ataxia type 28, JAMA Neurol 72(1) (2015) 106-11.

[3] L. Szpisjak, V.L. Nemeth, N. Szepfalusi, D. Zadori, Z. Maroti, T. Kalmar, L. Vecsei, P. Klivenyi, Neurocognitive Characterization of an SCA28 Family Caused by a Novel AFG3L2 Gene Mutation, Cerebellum 16(5-6) (2017) 979-985.

[4] C. Cagnoli, C. Mariotti, F. Taroni, M. Seri, A. Brussino, C. Michielotto, M. Grisoli, D. Di Bella, N. Migone, C. Gellera, S. Di Donato, A. Brusco, SCA28, a novel form of autosomal dominant cerebellar ataxia on chromosome 18p11.22-q11.2, Brain 129(Pt 1) (2006) 235-42.

[5] U. Edener, J. Wollner, U. Hehr, Z. Kohl, S. Schilling, F. Kreuz, P. Bauer, V. Bernard, G. Gillessen-Kaesbach, C. Zuhlke, Early onset and slow progression of SCA28, a rare dominant ataxia in a large four-generation family with a novel AFG3L2 mutation, Eur J Hum Genet 18(8) (2010) 965-8.

[6] S. Tunc, M. Dulovic-Mahlow, H. Baumann, M.K. Baaske, M. Jahn, J. Junker, A. Munchau, N. Bruggemann, K. Lohmann, Spinocerebellar Ataxia Type 28-Phenotypic and Molecular Characterization of a Family with Heterozygous and CompoundHeterozygous Mutations in AFG3L2, Cerebellum 18(4) (2019) 817-822.

[7] M. Manto, D. Marmolino, Cerebellar ataxias, Curr Opin Neurol 22(4) (2009) 419-29.

[8] G. Coarelli, A. Brice, A. Durr, Recent advances in understanding dominant spinocerebellar ataxias from clinical and genetic points of view, F1000Res 7 (2018). 
[9] Y.M. Sun, C. Lu, Z.Y. Wu, Spinocerebellar ataxia: relationship between phenotype and genotype - a review, Clin Genet 90(4) (2016) 305-14.

[10] M.U. Manto, The wide spectrum of spinocerebellar ataxias (SCAs), Cerebellum 4(1) (2005) 2-6.

[11] D. Di Bella, F. Lazzaro, A. Brusco, M. Plumari, G. Battaglia, A. Pastore, A. Finardi, C. Cagnoli, F. Tempia, M. Frontali, L. Veneziano, T. Sacco, E. Boda, A. Brussino, F. Bonn, B. Castellotti, S. Baratta, C. Mariotti, C. Gellera, V. Fracasso, S. Magri, T. Langer, P. Plevani, S. Di Donato, M. Muzi-Falconi, F. Taroni, Mutations in the mitochondrial protease gene AFG3L2 cause dominant hereditary ataxia SCA28, Nat Genet 42(4) (2010) 313-21.

[12] P.M. Quiros, T. Langer, C. Lopez-Otin, New roles for mitochondrial proteases in health, ageing and disease, Nat Rev Mol Cell Biol 16(6) (2015) 345-59.

[13] M. Nolden, S. Ehses, M. Koppen, A. Bernacchia, E.I. Rugarli, T. Langer, The m-AAA protease defective in hereditary spastic paraplegia controls ribosome assembly in mitochondria, Cell 123(2) (2005) 277-89.

[14] L. Atorino, L. Silvestri, M. Koppen, L. Cassina, A. Ballabio, R. Marconi, T. Langer, G. Casari, Loss of m-AAA protease in mitochondria causes complex I deficiency and increased sensitivity to oxidative stress in hereditary spastic paraplegia, J Cell Biol 163(4) (2003) 777-87.

[15] F. Maltecca, E. Baseggio, F. Consolato, D. Mazza, P. Podini, S.M. Young, Jr., I. Drago, B.A. Bahr, A. Puliti, F. Codazzi, A. Quattrini, G. Casari, Purkinje neuron Ca2+ influx reduction rescues ataxia in SCA28 model, J Clin Invest 125(1) (2015) 263-74.

[16] J. Qu, C.K. Wu, J.R. Zuzuarregui, A.D. Hohler, A novel AFG3L2 mutation in a Somalian patient with spinocerebellar ataxia type 28, Journal of the neurological sciences 358(1-2) (2015) 530-1.

[17] Z. Musova, M. Kaiserova, E. Kriegova, R. Fillerova, P. Vasovcak, A. Santava, K. Mensikova, A. Zumrova, A. Krepelova, Z. Sedlacek, P. Kanovsky, A novel frameshift mutation in the AFG3L2 gene in a patient with spinocerebellar ataxia, Cerebellum 13(3) (2014) 331-7.

[18] K. Smets, T. Deconinck, J. Baets, A. Sieben, J.J. Martin, I. Smouts, S. Wang, F. Taroni, D. Di Bella, W. Van Hecke, P.M. Parizel, C. Jadoul, R. De Potter, F. Couvreur, E. Rugarli, P. De Jonghe, Partial deletion of AFG3L2 causing spinocerebellar ataxia type 28, Neurology 82(23) (2014) 2092-100.

[19] C. Mariotti, A. Brusco, D. Di Bella, C. Cagnoli, M. Seri, C. Gellera, S. Di Donato, F. Taroni, Spinocerebellar ataxia type 28: a novel autosomal dominant cerebellar ataxia characterized by slow progression and ophthalmoparesis, Cerebellum 7(2) (2008) 184-8.

[20] A. Brussino, A. Brusco, A. Durr, C. Mancini, Spinocerebellar Ataxia Type 28, in: M.P. Adam, H.H. Ardinger, R.A. Pagon, S.E. Wallace, L.J.H. Bean, K. Stephens, A. Amemiya (Eds.), GeneReviews((R)), Seattle (WA), 1993.

[21] H.A.G. Teive, W.O. Arruda, Cognitive dysfunction in spinocerebellar ataxias, Dement Neuropsychol 3(3) (2009) $180-187$.

[22] V.M. Miller, H. Xia, G.L. Marrs, C.M. Gouvion, G. Lee, B.L. Davidson, H.L. Paulson, Allele-specific silencing of dominant disease genes, Proceedings of the National Academy of Sciences of the United States of America 100(12) (2003) 7195-200.

\section{Figures}




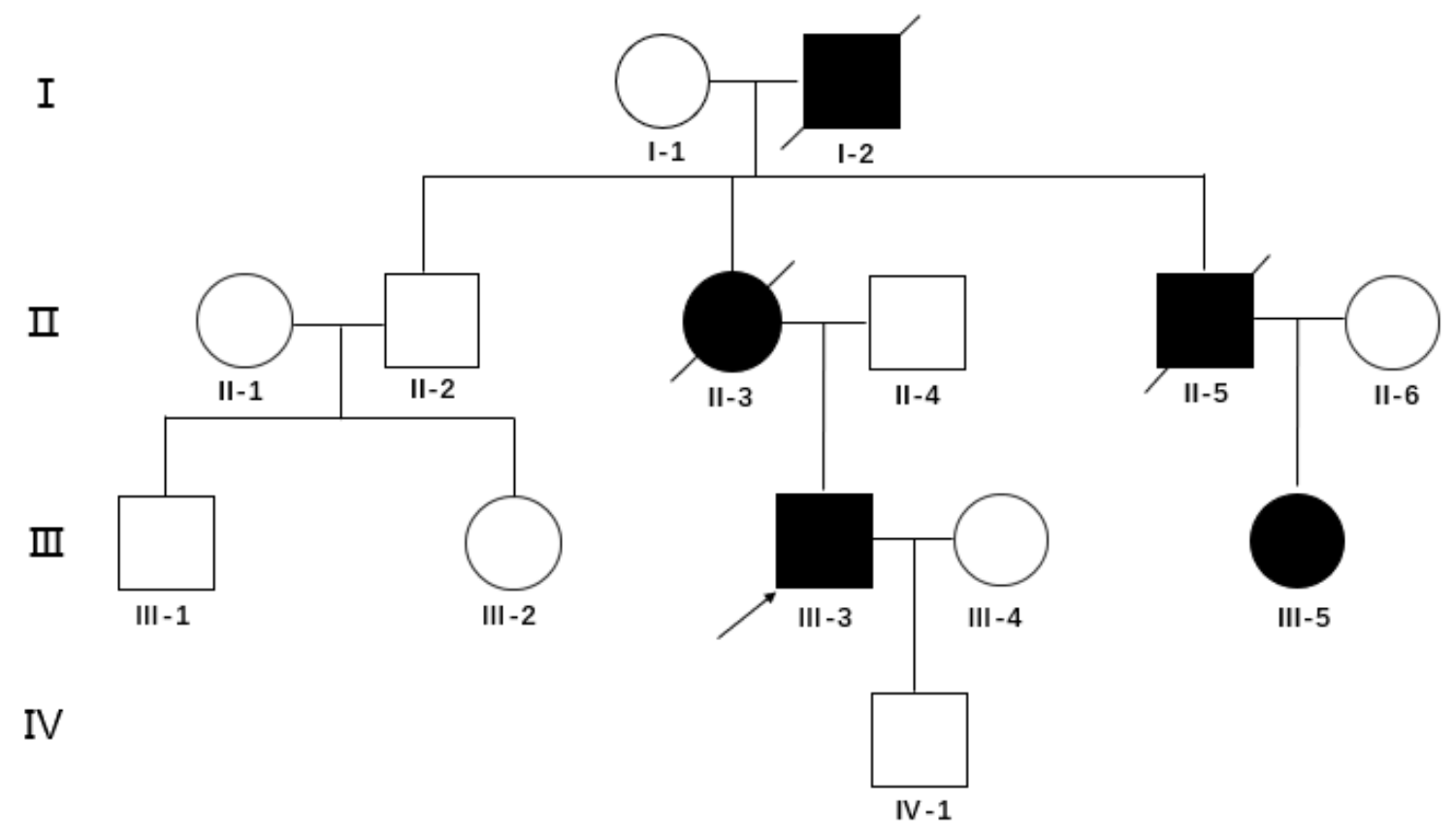

Annotation: Healthy men $\square$ : Healthy women $\bigcirc$ : Sick male $\square$ : Sick women $\bigcirc$ : Proband $/$ : Death $/$ :

Figure 1

Pedigree Map

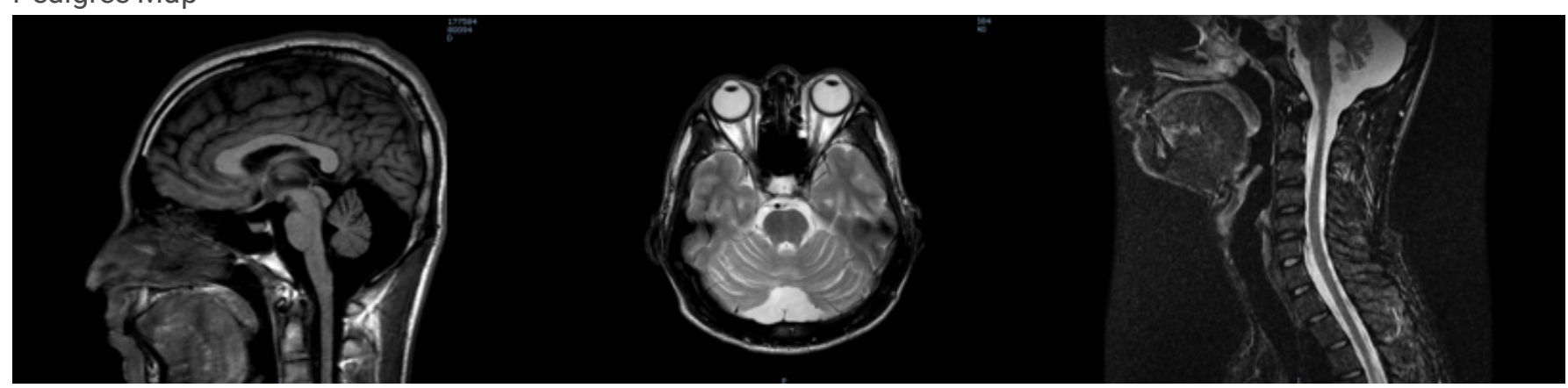

Figure 2

Head MRI of the proband (III-3) showed cerebellar atrophy with no obvious abnormal signals in the rest. Cervical MRI showed no atrophy or thinning in cervical cord, and no obvious abnormal signal was found.

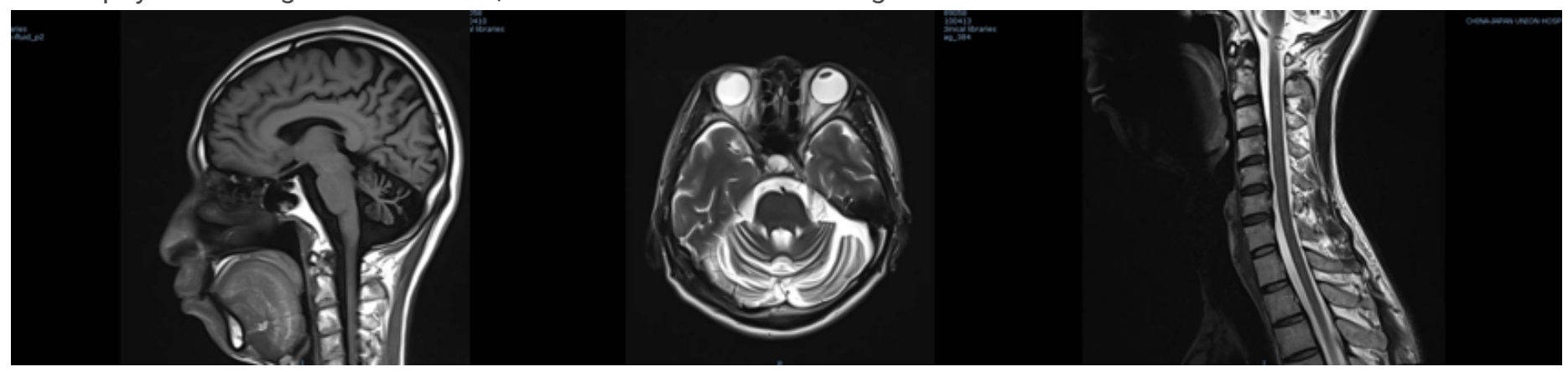

Figure 3 
Head MRI of the patient III-5 showed cerebellar atrophy with no obvious abnormal signals in the rest. Cervical MRI showed no atrophy or thinning in cervical cord, and no obvious abnormal signal was presented.

A G C T G C T C T T T G G TA TAG A G G

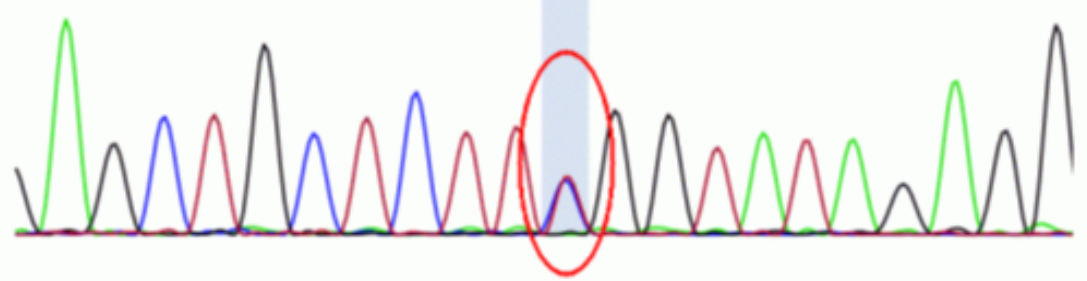

\section{Figure 4}

Proband (III-3) gene sequencing

A G C T G C T C T T T G G TA TA G A G G

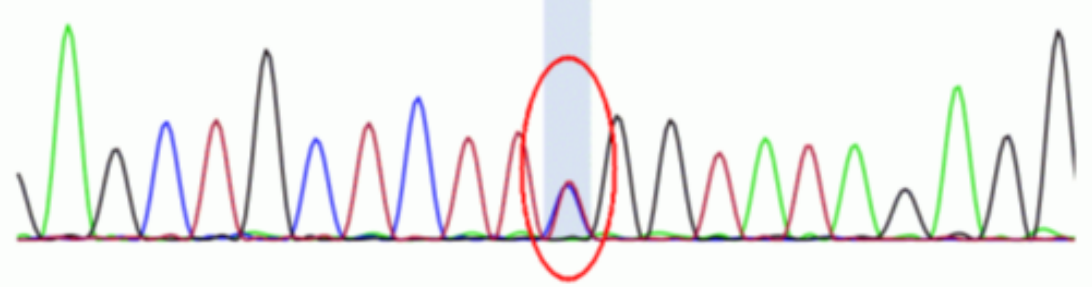

Figure 5

Patient III-5 gene sequencing 